\title{
Tourist Attraction Development Modeling: Public Sector Policy and Management Case
}

\author{
Roger R. Stough* and Mary Feldman**
}

\section{INTRODUCTION}

The expanding role of leisure in post industrial society has produced a significant increase in tourist activity over the last decade at both the national and international level. This increase coupled with the observation that economic benefits accrue much faster from tourism than from many other capital intensive industries (Cleverdon, 1979) has made tourism a major element in many economic, development plans at the urban, regional, state and national levels. As a consequence, tourism development has been and continues to be an especially prominent feature of economic development planning for declining as well as growth cities in the United States and of the lesser developed countries.

While a developing tourism industry tends to have immediate or near term payoffs (employment, income, and facilities) for a city or a region it has also frequently produced negative impacts especially in the longer term. This pattern may be described in terms of an evolutionary model of development: tourist areas are viewed as first passing through a nascent stage of development, and then through a rapid period of expansion which then stabilizes asymptotically and frequently exhibits decline thereafter (see Butler, 1980). Urban and regional planners and policy-makers have not fully appreciated the impacts associated with the different stages of this development pattern. This may be viewed as a major reason for the past decline of heavily tourist dependent cities like Miami, Florida and Atlantic City, New Jersey. That some tourist areas that have experienced stagnation and decline have recently experienced "rejuvenation" suggests that the impacts of an expanding tourism industry on its urban and regional environment can be more evenly managed.

\#An earlier version of this paper was presented at The Atlantic Economic Society annual conference in Miami Beach, Florida, October 8, 1982.

"School of Public and Environmental Affairs, Indiana University

*: Visitor Information Center, Charleston, South Carolina 
The purposes of this paper are:

1) to review and analyze the evolutionary model of tourism development;

2) to explore the public policy and public management implications of the evolutionary model; and

3) to examine the public policy and public management implications of the evolutionary model using Charleston, South Carolina as a case study.

Before addressing these topics it is important to describe the somewhat unique nature of the tourism industry and the types of positive and negative impacts that a tourist area may experience.

\section{THE NATURE AND IMPACT OF THE TOURISM INDUSTRY}

The tourism industry may be defined as consisting of those businesses that provide services for tourists. It is unlike many other industries in that it delivers a highly diverse product through the efforts of many other industries, e.g., travel and transportation, lodging, entertainment, food, clothing, and retail trade. Each of these contributing industries have clientele other than tourists and, as a consequence, tourism may be viewed as a synthetic industry. In short it consists almost completely of other industries. This creates special problems for the study of the industry not the least of which is that of identifying, for a given locale, that portion of trade that is tourist related for each associated industry.

Tourism is attractive as a focal point of urban and regional economic development planning because the benefit stream from tourist related development begins almost immediately (see Table 1). Direct benefits occur in the form of employment, income and tax revenues. Through these direct effects multiplier effects are established. Additionally tourism may serve to expand the availability of amenities to local residents, to broaden the local residents' world view, and to make the city or region more visible and, therefore, more politically viable (Richter, 1980).

The development of a tourism industry in an area produces in varying degrees a variety of negative economic, social and environmental impacts (see Table 1). Most of these are not experienced initially but at a later time when the industry matures. Of those negative impacts that may occur during the early stages of development the low skill and associated low pay nature of many tourism generated jobs is the most prominent. Also returns on investment may be "leaked" in large part out of the regionespecially in developing countries. Despite these attributes of the industry most negative impacts do not occur until the later stages of attraction development. These later stage impacts may include: 1) competition for services between locals and visitors (especially where the industry is seasonal); 2) property taxes may increase due to rising land values with the impact of this falling most heavily upon those with fixed incomes; 3) increased demand for services; 4) tourist encroachment on private property; 5) erosion of host community culture; and, 6) physical environment 
TABLE 1.

MAJOR TOURISM IMPACTS AT THE LOCAL AND REGIONAL LEVELS

\section{Benefits}

1. Source of Employment

2. Source of income

3. Source of tax revenue

4. May diversify economic base

5. Expands amenity availability for local residents

6. May make area more visible

\section{Costs}

1. Most jobs are low paying

2. Much of the return on tourism investment may be leaked out of local economy

3. Seasonal-may frequently be a high risk industry

4. Competition for services between local and outsiders especially where seasonality is a factor

5. Increased land values may stress locals especially those on fixed incomes

6. Tourists may disproportionately increase service demands due to water, air and noise pollution

7. Encroachment on private property

8. Erosion of host community culture

9. Ecological demands, e.g., lowering availability of water in coastal areas due to draw down on ground water

deterioration due to air, water, noise pollution and resource depletion (OECD, 1980).

The importance of our above discussion is that it portrays the tourism industry as one that promises many economic benefits quickly, thereby obscuring the fact that negative impacts usually emerge during the later and more mature stages of a tourist area's development. The failure to perceive in the early stages of development that later stages will bring negative impacts and the failure to plan accordingly may be viewed as contributing to the decline that tourist areas frequently experience in their later stages of development.

\section{AN EVOLUTIONARY MODEL OF TOURIST AREA DEVELOPMENT AND IMPACT}

Tourist areas are dynamic. As described above, they emerge, evolve, expand, and change over time. Several factors are responsible for this. These include "changes in the preferences and needs of visitors, the gradual deterioration and possible replacement of physical plant and facilities, and the change (even disappearance) of the original natural and cultural attractions which are responsible for the initial popularity of the area" (Butler, 1980, p. 5). Of particular significance is the observation that the 
TABLE 2.

Attraction Development Stages, Tourist Typologies and Community/Cultural Changes

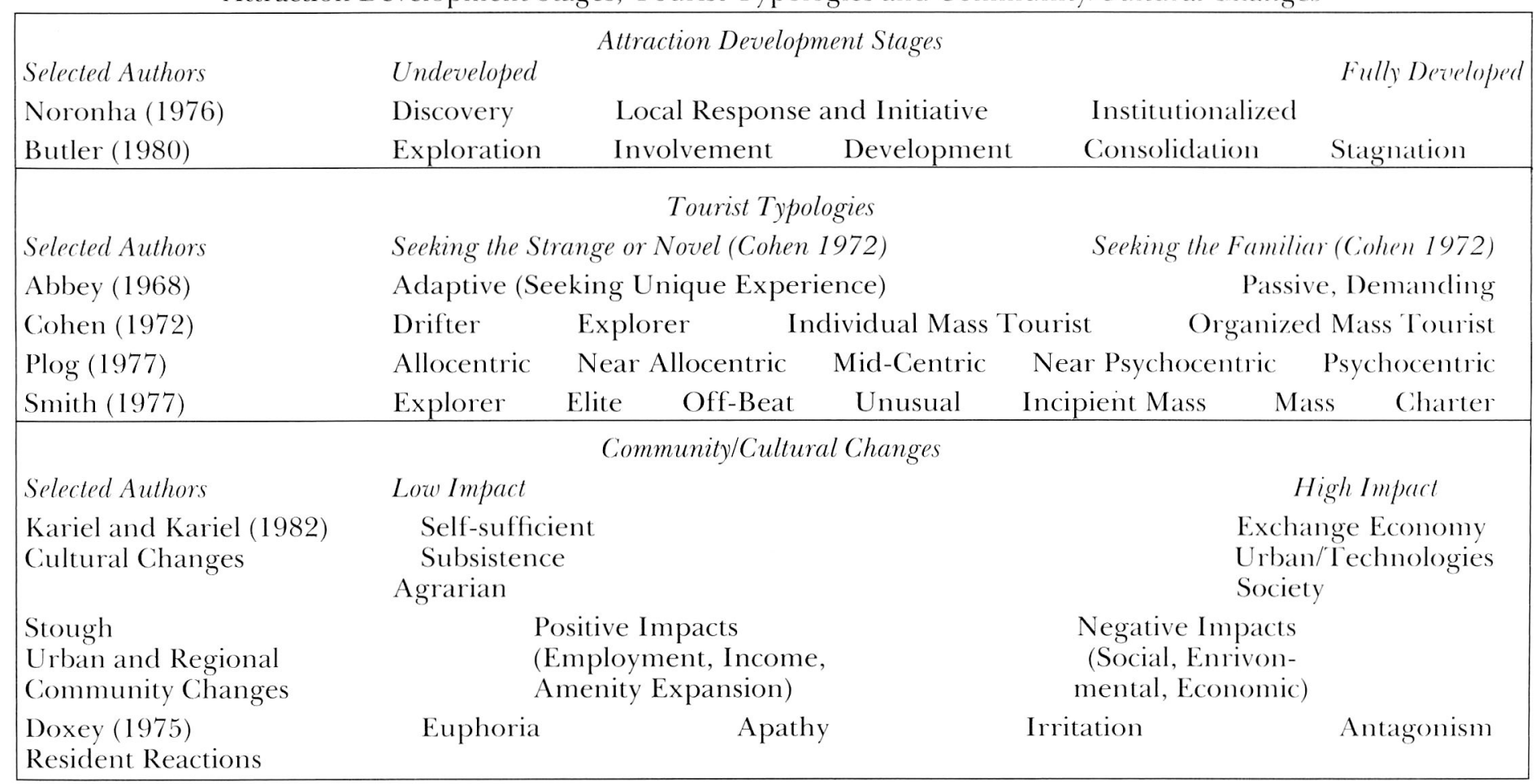


type and volume of tourists, host culture changes, community changes and resident reaction to tourists vary in a predictable manner with stages of tourist attraction development (see Table 2). In Table 2 we explore and describe the relationships among these factors.

Many authors including Butler (1980), Noronha (1976) and Stansfield (1978) have observed that tourist attraction areas pass through seemingly predictable stages. Butler's (1980) formulation is based on a marketing concept-the product cycle. The product cycle is similar in all but its final stage-decline-to the acceptance cycle that successful new innovations experience (see Rogers, 1962). Sales or adoptions occur slowly at first, then expand rapidly, and stabilize asymtotically. The final stage of the product cycle is decline and while this occurs in the life history of many tourist areas it does not always occur. As Reime and Hawkins (1979) note, once the growth of the industry has stabilized in a region it is likely that some decline will be experienced. However, the stabilized level may be maintained indefinitely or rejuvenation may occur. The reason that decline frequently occurs following stabilization is found in the belief that different types of visitors are drawn to attractions at different stages of development. The types of visitor that appear during Butler's consolidation and stagnation stages are viewed as contributing to decline.

Many authors have developed tourist typologies (see Table 2). The underlying dimension of these typologies may be described as anchored on one end by the visitor seeking strangeness and novelty and on the other by the visitor who, while desiring travel, wishes to do so within the context of familiar surroundings. The unique and strange can best be experienced during the nascent or "exploration" stage of a tourist area's development, while a familiar environment is more easily experienced once an area has become well developed, e.g., Butler's consolidation stage. While the tourist typologists, e.g., Abbey (1968), Cohen (1972), Plog (1974), and Smith (1977), all order their typologies along this underlying dimension, Plog has developed his typology in a way that lends clarification to the relationship among the stages of tourist area development, the type of visitor and the community/cultural impact on an area. Plog (1974) identified five tourist types (allocentric, near allocentric, mid-centric, near psychocentric and psychocentric) and through subsequent research the proportion of each type that exists in the general population was estimated.

Plog's allocentric individual is similar to Cohen's (1972) drifter and Smith's explorer. Allocentrics seek vacation environments which are totally different from their normal environment wishing to see the vacation environment as it is. These visitors are discoverers and consequently rarely return to an area for a second visit. They comprise about 6 percent of the population (Reime and Hawkins, 1979).

The near-allocentric individual represents approximately 15 percent of the population (Reime and Hawkins, 1979). The near-allocentric is similar to the allocentric person in that he wishes to see and interact with an area as it is. He is different in that some accommodations are desired, e.g., lodging and restaurants intended to serve tourists. The near-allocentric travels often and "works" to discover new places. 


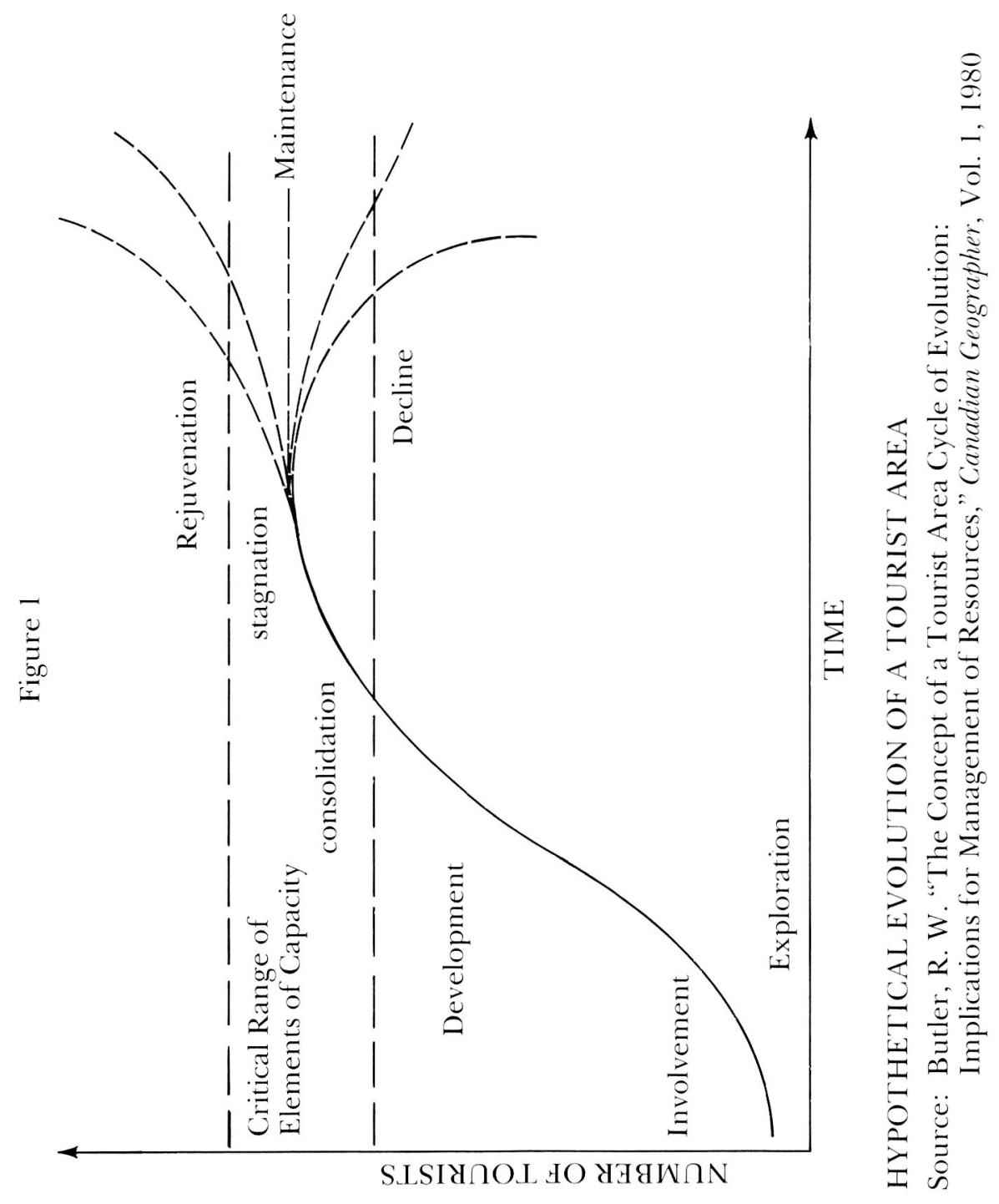


Figure 2.

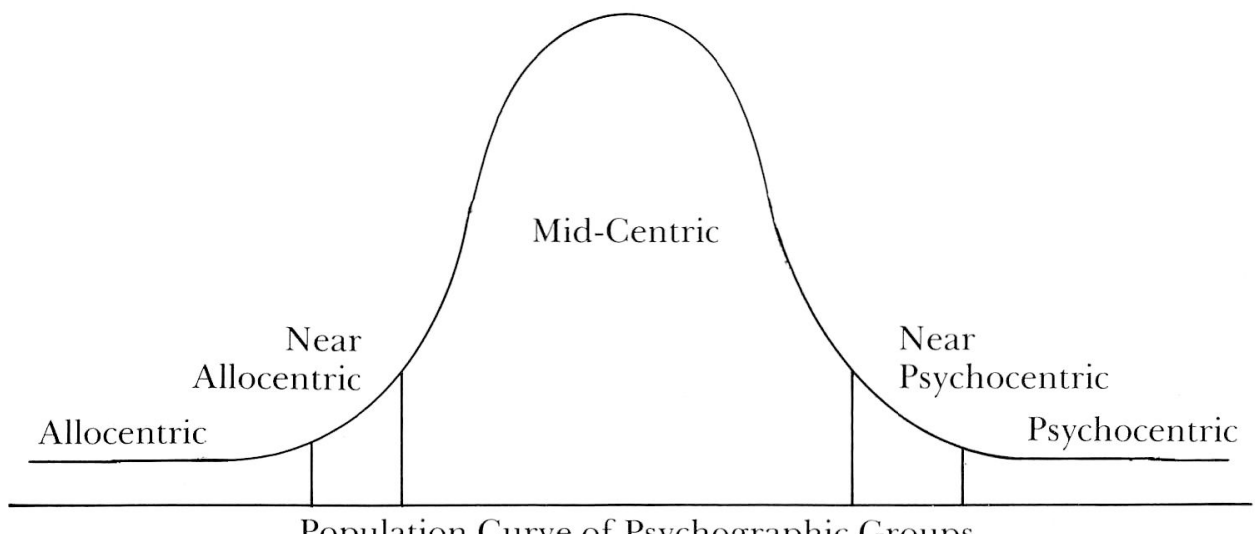

Population Curve of Psychographic Groups

Source: Plog, S.C. "Why Destination Areas Rise and Fall in Popularity." Unpublished paper presented to the Southern California, The Travel Research Association, 1972.

The largest group, the mid-centric comprises about 60 percent of the population (Reime and Hawkins, 1978). Researchers (Plog, 1974 and Reime and Hawkins, 1979) speculate that this type of person seeks "security" and "peer approval" and as a consequence, seeks a well developed tourist area with a variety of commercial attractions. In contrast, however, the more extreme near-psychocentric visitor requires not only a high density commercial attraction environment but seeks tourist areas with an abundance of modern chain hotels, family restaurants, souvenir shops. Typically this visitor seeks non-foreign attractions and generally those that are easy to reach by automobile.

Finally, the psychocentric individual seeks highly familiar areas. They tend to enjoy resort areas, amusement parks, family restaurants and souvenir shops. Psychocentrics require that the attraction environment be contrived to suit their interests. This type visitor tends to be a repeat visitor.

Returning now to Butler's (1980) evolutionary model we may characterize the development of an area's tourism industry and its impact as follows (the reader is also referred to Table 2):

1) Exploration Stage: This stage is characterized by small numbers of visitors-most of which are Plog's allocentrics who have made their own arrangements. At this stage investment in visitor facilities would not have occurred. Because visitors are dependent on their own devices for lodging, eating and entertainment services they tend to have considerable interaction with local residents. In short, the physical, economic, social and cultural makeup of the area would remain unchanged by tourists during this stage. 
2) Involvement Stages: As the allocentric returns and begins to share information about his visit with others, more visitors-Plog's near-allocentrics-begin to arrive in the area. In response to this some local residents begin to produce services for visitors and some advertising may ocur. Contact among visitors and locals remains high. During the involvement stage a small tourist season may emerge as well as an effort to organize travel and accommodation arrangements. While the impacts on the area are minimal during this stage some do begin to occur: 1) the emergence of a tourist season will induce some changes in social and living patterns for at least those involved in providing tourist services; 2) additional income and employment opportunities for those families providing tourist services is noticeable; and 3) demand for improved transportation connections and facilities begin to be registered with government agencies. Information in Table 2 and Figure 3 illustrate additional impacts that may occur during the involvement stage especially in underdeveloped countries.

3) Development Stage: During this stage the area emerges as a major tourist market area experiencing a tourist population at peak periods that may be larger than the local population. The area, consequently becomes dependent on extension advertising in tourist generating areas. Local involvement and control in developing and producing tourist services declines. Although some local facilities will be maintained, many will be replaced by larger, more modern ones built with externally generated and controlled capital. The natural and cultural features that served as the initial attraction will be heavily marketed and new man-made, i.e., artificial features, will be introduced. While significant positive economic benefits and amenities accrue to local residents during this stage, major physical environment, social and cultural impacts occur especially during the latter part of the development stage. In short, as this stage unfolds a major transformation of the local environment and culture occurs: local control is lost; social patterns and life styles are compromised and changed; and, the built environment becomes dense and modern (see Table 2 and Figure 3). During this stage local residents begin to convey irritation (Doxey, 1975 ) with the transformation of their area. Over this period the type of tourist changes also. Modern facilities mean that the area offers more of the familiar and consequently Plog's mid-centrics increasingly replace the more independent and exploratory near-allocentric.

4) Consolidation Stage: During this stage the rate of increase of visitors declines but overall numbers increase and peak visitor numbers exceed the local population. The economic impact of the tourism industry becomes a major part of the area's economic base and advertising becomes a major and highly institutionalized activity with a significant effort made to extend the season and the market area. Chain hotels, restaurants and attractions are conspicuous. Resident reaction becomes more action oriented than in the previous stage, e.g., antagonism (Doxey, 1975). Plog's near-psychocentric visitor is present during this stage.

5) Stagnation Stage: When this stage is reached the area's attraction will have peaked. Capacity for many factors such as attractive development locations, public services and associated environmental, social and eco- 
Credit-Monetary Exchange Economy

Urban Oriented

Technological

Society

Self-sufficient

Subsistence level

Agrarian society
- increased knowledge of outside world

- more time spent with guests and less with famply

- increased rigidity of working hours

- children help less around home and farm

- wife earns increasing share of income/
- paid labor replaces volunteer-cooperative community work

- children participate in sports

- conceptual employment

and unemployment appears

- opportunities proxided for employment

and housing for adult children in community

- major share of income earned by wife, with

accompanying role change

- in-migration of workers

- increased Marriage breakdown

- holidays taken away from home

- revival of traditional customs and language patterns

- decreased emphasis on religion

- decrease in family size

- increased educational level

- slowing of outmigration

- competition among individuals replaces

cooperation

- improved medical care

- more shopping outside lofal community 
nomic problems are manifest. During this stage the area has a well established image but may become unfashionable (e.g., Acapulco, Atlantic City before gambling and Asbury Park). Consequently surplus or unused capacity may occur and extensive efforts are required to maintain visitor volume if indeed it can be maintained. During this stage the area becomes more dependent upon its artificial attractions and frequently its image is separated from the original genuine natural and cultural attractions. To the extent that new development occurs it is peripheral to the original core attraction area. As the stagnation period evolves the type of visitor changes with Plog's psychocentric becoming more conspicuous.

6) Post Stagnation Stage: As an area adjusts to stagnation it may experience one of the three general longer term outcomes: rejuvenation, maintenance or decline. In decline which many view as the most frequent medium term outcome (Butler, 1980), the area looses its ability to compete with other newer attractions for the mid-centric visitor type and, consequently, appeals primarily to day or weekend visitors if the area is accessible to these types. Property turnover and vacancy rates are high and, consequently, properties are converted to other non-tourist uses, e.g., retirement facilities or nursing homes. If this process is cumulative then the viability of the remaining tourist facilities is compromised even further.

Rejuvenation of an area's stagnant tourism industry usually occurs in one of two ways. First, an area may strike upon a new "artificial" attraction such as gambling which some view as having revitalized Atlantic City (Downey, 1982). Others disagree however (Tantillo, 1982). The second way in which rejuvenation may occur is through developing a previously undeveloped natural attraction or resource for example, "spa towns in Europe and the summer holiday village of Aviemore in Scotland have" .. . reoriented ... "to the winter sports market, thus allowing the areas to experience a year-round tourist industry." (Butler, 1980, p. 9).

Maintenance is perhaps the most desirable state for an area once it has reached the stagnation level. Ideally an area would like to maintain itself once the phyical and institutional infrastructure has been built. To do this requires extensive physical and institutional reinvestment in order to repair and modernize. This is not likely to happen if an area passes through the evolutionary process described above. A reason for this is that the return on investment for modernization-which frequently must be made by national or multi-national level corporations (those which typically control attractions in the latter stages) - may be less than for similar investments in new or emerging attraction areas. Areas that are most likely to be maintained are those that reach the consolidation and stagnation stages prematurely thus stabilizing facilities at a level that is attractive to Plog's near-allocentrics and mid-centrics.

The above stylized description of Butler's (1980) evolutionary view of tourist attraction evolution identifies a number of focal points for public policy concern. Each stage as well as the probable outcomes of the process for the local area raise important policy issues. These are discussed below. 


\section{THE PUBLIC POLICY IMPLICATIONS OF THE EVOLUTIONARY MODEL OF TOURIST AREA DEVELOPMENT}

The description of Butler's (1980) evolutionary model was presented in a stylized manner. If, however, we take that description at face value it would appear that Butler and the present authors are advocating a unilinear model of social change at least through the stagnation stage. While others have warned against this (Cohen, 1972), particularly with regard to developing tourist areas, the evidence, admittedly sketchy and incomplete, strongly supports a pattern consistent with the evolutionary model. Therefore, while we recognize that there is a need to more fully test this model, it is nonetheless important to consider the public policy implications of the formulation.

Clearly one major arena for public policy concern lies with the poststagnation period. The critical questions are which policies at the urban and regional levels are best for: 1) avoiding decline or managing it where it cannot be avoided; 2) rejuvenating a stagnant and/or declining attraction area; and, 3) maintaining an attraction area once growth (stagnation) ceases. These are problems that we are familiar with as they are the problems of declining cities and metropolitan areas (it is important to note that the cause for decline in the U.S. cities is related to interregional shifts of resources and other exogenous factors rather than "aging" tourist industries). At the same time it is interesting that policies aimed at expanding tourist and convention trade have been adopted by many Northeastern and Northcentral industrial cities to either combat decline or to promote maintenance and rejuvenation. Despite the very interesting nature of the problems and, therefore, policy questions associated with the post stagnation period we have chosen not to deal with them in this paper. Rather our attention is focused on the part of the process that appears to follow a predictable pattern, i.e., up to and including stagnation.

The evolutionary process of tourist area development may be described by the logistic equation, i.e., the S-shaped curve. When adapted to tourist area development the equation may be stated as:

$$
\begin{aligned}
& \mathrm{Y}=\frac{\mathrm{L}}{\mathrm{l}+\alpha \mathrm{e}^{-\beta 1}} \\
& \begin{array}{l}
\text { where } \mathrm{Y}=\text { Number of tourists. } \\
\mathrm{t}=\text { Time. } \\
\mathrm{L}=\text { The number of tourists at stagnation. } \\
\beta=\text { Rate at which visitors increase over time. } \\
\alpha=\text { Initial number of visitors. }
\end{array}
\end{aligned}
$$

In short, the logistic equation is a mathematical model of the tourist area 
development process. Consequently, there are really only two underlying dimensions upon which poliy can focus. These are: $\mathrm{L}=$ the number of tourists at stagnation; and, $\beta=$ rate at which the attraction area develops.

Today $\beta$ is frequently manipulated through government policy. For example, the Cancun area in Mexico was conceived, developed, and marketed effectively all within a few years. Today Cancun is well into the development stage of the process. This trend reflects an emerging policy problem in that benefits occur much sooner than during previous times and the negative impacts associated with the advanced stages of the process may occur much more quickly also.

The evidence that we have of attraction development suggests that we should be devising policies that aim at lowering the level (L) at which industry growth stagnates. That many attraction areas suffer partial or permanent decline after reaching the stagnation stage is probably induced by overinvestment which in turn generates the negative economic, social and environmental impacts listed in Table 2. The following discussion of the relationships in Figure 4 helps to explain why overinvestment occurs and in turn why the associated negative impacts occur.

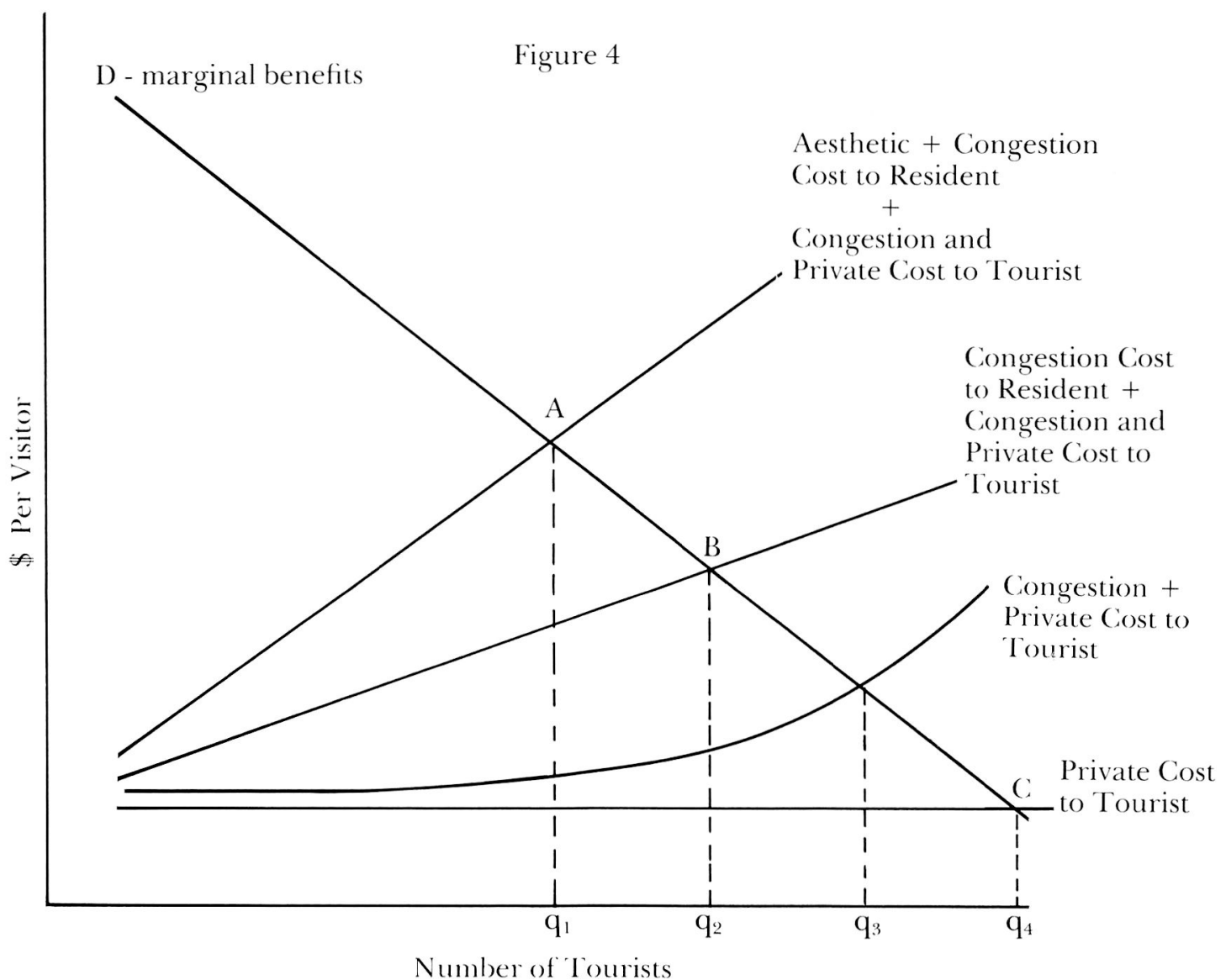

Number of "Iourists 
In Figure 4, marginal benefits to the visitor are viewed as decreasing with increasing numbers of tourists while marginal costs of providing direct services for the tourist are treated as constant. (Note that benefits to the marginal tourist may be constant as long as tourist volume remains small attracting primarily Plog's allocentrics). Consequently, the laissez faire businessman would argue that the industry should expand to serve $\mathrm{q}_{4}$ number of tourists, i.e., it should expand to the level where the marginal benefits to the tourists equal the marginal costs (Point $\mathrm{C}$ ). This, however, discounts the public cost that the expanding industry creates, e.g., congestion cost to both the visitor and the resident, encroachment on private property, and other social, economic and environmental impacts. In this model, public costs are viewed as increasing with visitor volume. Consequently, the more altruistic entrepreneur would tend to argue that only $\mathrm{q}_{2}$ number of tourists should be sought. Room or accommodations taxes are frequently used to generate funds to compensate public costs. Finally, preservationists would argue that the number of tourists should be somewhat less than $q_{2}$, perhaps $q_{1}$. Their more restrictive position is not rationalized directly in terms of market arguments but in terms of aesthetics. Consequently, they are more likely to argue that the number of tourists should be controlled by quota.

The most defensible position economically is that of the altruistic businessmen in that s/he would argue for that volume of tourists where the benefit to the marginal tourist equals the marginal cost of providing services to the tourist plus the marginal public cost to tourist and the attraction area's population. Our discussion above suggests that this does not occur, i.e., that the process of tourist area development continues well past $\mathrm{q}_{2}$, perhaps even beyond $\mathrm{q}_{4}$, before it stagnates with a host of negative economic, social and environmental impacts. We believe that this frequently occurs for the following reason: benefits from tourism are soon to occur as the area's nascent industry grows and passes into the developmental stage. But only in the later phases of the development stage, when visitor volume may be greater than $\mathrm{q}_{2}$, are the major negative impacts readily perceived. By this stage it is too late. It is too late to take down the excess of hotels, motels, marinas, attractions and restaurants. Consequently, a set of management tools is needed to stabilize the process of tourist area development at some level below that that the area would otherwise move toward $\left(q_{4}\right)$.

\section{PUBLIC MANAGEMENT IMPLICATIONS OF THE EVOLUTIONARY MODEL OF TOURIST AREA DEVELOPMENT}

A model showing the relationships among the major components of an area's tourism industry is outlined in Figure 5. This model indicates that the volume of tourists coming to an area creates economic, social and environmental impacts. While these impacts probably cannot be managed by directly controlling the number of visitors the model does suggest that control can be achieved through management policies directed toward;1) 


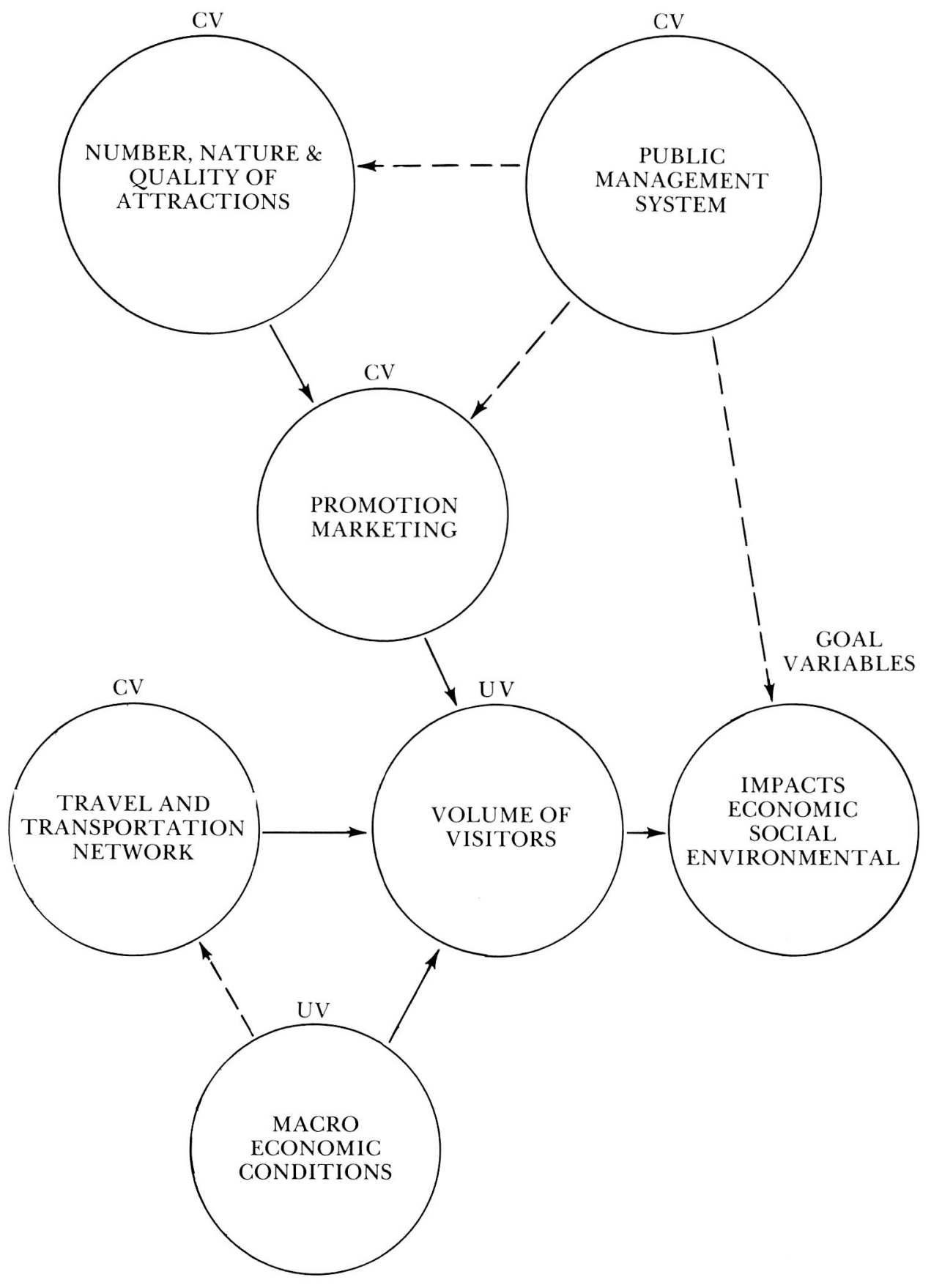

$\mathrm{CV}=$ Variable that can be controlled by local policy makers

$\mathrm{UV}=$ Variable that cannot be controlled by local policy makers

Figure 5 
attraction maintenance and development; 2) promotion and marketing; and, 3) local and regional transportation network development. A carefully developed management system could also directly affect the impact of economic, social and environmental impacts. In the following discussion, a variety of public tourism management strategies and tools are described.

There are at least 4 ways government can provide leadership for an area's tourism industry. These are: 1) rule setting; 2) proprietary; 3) partnership; and 4) supportive. Public management tools and strategies associated with each of these roles are outlined below.

\section{Rule Setting Role}

The strongest power government has for managing the growth and impact of its tourism industry is in its power to enact rules or laws, e.g., zoning ordinances, traffic regulations, building codes, permits, regulations and taxation. Zoning ordinances may be used to control impacts through influencing industry location decisions (see Gunn, 1979). Building codes and enforcement may serve to provide the basis for inducing adequate facility maintenance. Traffic regulations may be used to manage congestion and other impacts through routing of tours and vehicles and parking sites. Taxation, e.g., on accommodations or sales tax may serve to provide resources to pay for and thereby reduce the impact of public costs on both the tourist and the resident. In addition to these possibilities, governments have the power to create entities, e.g., boards, commissions or authorities, which can actively regulate and/or promote tourist activity. Many tourist cities and towns in the U.S. have employed these and other tools.

\section{Proprietary Role}

Government has the power to create corporate entities to provide goods and services. This typically occurs when the scale of the goods or service is very large, e.g., water supply or production of hydro-electricity or when the risk or uncertainty associated with producing the good or service is very high. With regard to this role, then community tourism development corporations and authorities have been developed to help our area improve economic conditions. Some areas have established entities that assume the responsibility for promoting tourism and for providing some services, e.g., operating visitor reception centers and providing other limited services.

\section{Partnership Role}

In this role, governments may offer tax breaks, franchise options, contract with a private provider to provide services, e.g., lease operation of a visitor information center to a private operator, when they wish to support industry development. At the same time, each of these activities can be used to manage and control impacts since contingency clauses and other requirements can be attached as part of the agreement. 


\section{Supporting Role}

In this role, government is seen as having indirect involvement. This may include actions such as financial and other support for local training and education related to the industry's growth and impact. It may also involve supporting the development and maintenance of an information base that can support both public and private sector planning.

Charleston, located on the southeast coast of the United States, experienced little economic growth during the 100 years following the Civil War. Consequently, when historic preservation became popular in the 1960's much of downtown (peninsula) Charleston became a prime target for preservation. As preservation efforts gained momentum Charleston was discovered. By the late 1960's and early 1970's visitor volume to the City had increased to a level whereby an emerging tourism industry was identifiable. During the mid-late 1970's the City had become the host of the Miss America Contest and the host of the Spoleto Festival. In short, the Charleston "attraction" was viewed as being in the development stage of attraction evolution.

The key attraction in Charleston is and has been the historic core city which consists of about 100 blocks bounded on three sides by water. The physically constrained nature of this attraction meant that visitors were far more concentrated then would have been the case for a more decentralized attraction. Consequently, negative impacts such as noise pollution, foundation vibrations created by passing tour buses and territorial encroachment of visitors on residential private property were far more quickly perceived and treated as community problems than would have been the case for a more decentralized community. In short, the negative impacts of tourism were perceived at a much earlier stage then would otherwise have been the case. Attempts to address these through public policy and management initiatives in turn occurred at an earlier stage than would otherwise have been the case.

In 1979, the Mayor of the City of Charleston formed a Tourism Management Study Committee and charged it with the development of a strategy that would alleviate impacts created by the growing tourism industry. The final report of that group (Mayor of Charleston's Tourism Management Study Committee, 1982) embodies a series of recommendations for the formation of a tourism management system. Key features of the system are:

1) Physical plans aimed at promoting economic development while at the same time concentrating visitors in a few locations.

2) A planned Visitor Reception Transportation Center (VRTC) designed to intercept, and educate auto travelers about the city and region and to place them on tours of the historic residential neighborhoods using other travel modes, e.g., small buses, carriages, and foot.

3) An attempt to develop outer-city attractions in an effort to reduce the pressure on the downtown area. 
4) The establishment of a Mayor's Office of Tourism Management with environmental managers trained to deal with many of the day-today impacts between residents and visitors, e.g., ordinance enforcement; crowd control; public relations.

5) A plan for coordinating promotion and marketing of public and private agencies with the goals of the overall tourism management plan.

6) New and revised ordinances which specify routes that are available to different types of tour vehicles and times of the day that touring may occur.

7) An operation plan for the VRTC that will control the number of tour vehicles that are operating in the historic area at any given time.

In addition, an information system has been developed and is maintained and updated annually by a local university. The system includes visitor profile information, origin/destination analyses and, economic, social and environmental impact analyses. The results of these analyses are published annually (see Stough, et al., 1984) and are used to facilitate public and private sector planning.

It is envisioned that the unfolding implementation of the Charleston tourism management plan will help to ensure that overinvestment in the tourism industry does not occur in Charleston. In short, it is anticipated that this plan will permit reasonable growth in the industry yet minimize its negative impacts.

\section{CONCLUSION}

The important policy and management question raised in this paper is not "how to manage a growing tourism attraction?" Rather it is to suggest that by the time policy makers in most tourist areas begin to recognize the need to manage, it is too late. The evidence we have strongly suggests that a greater initial (early) awareness and appreciation of the long term negative impacts of tourism development is needed on the part of area residents as well as local entrepreneurs. This can be accomplished in part through a greater dissemination of our knowledge, albeit imperfect, about the nature of the tourist area development process. Information about the Charleston, South Carolina case was presented to demonstrate that that community reached an awareness of the negative impacts associated with the final stages of tourist attraction development much earlier than has usually been the case in other attraction areas. This early awareness has however led to the creation of a management plan/system at a stage when it may be possible for the community to minimize negative impacts while at the same time enjoying the benefits of industry growth.

\section{REFERENCES}

Abbey, E. Desert Solitaire. New York: McGraw-Hill Book, Co. 1968.

Butler, R. "The Concept of a Tourist Area Cycle of Evolution: Implications for Management of Resources," Canadian Geographer, Vol. 1, 1980.

Cleverdon, R. The Economic and Social Impact of International Tourism on Developing Countries. EIU Special
Report No. 60, The Economist Intelligence Unit, Ltd. London, England, 1979

Cohen, E. "Towards a Sociology of International Tourism," Social Research, Vol. 39, 1972.

Downey, W. "Casino Gambling and the Redevelopment of Atlantic City." Paper presented at a conference at Stockton State College, Pamona, New Jersey, entitled 
"Atlantic City Tourism and Social Change," May 3, 1982.

Doxey, G. "Visitor-resident Interaction in Tourist Destinations: Inferences from Empirical Research in Barbados, West Indies and Niagra-on-the-Lake Ontario," Unpublished paper presented to the Symposium on the Planning and Development of the Tourist Industry in the ECC region, Dubrovnik, Yugoslavia, 1975.

Gunn, C. A., Tourism Planning, New York: Crane \& Russak \& Co., 1979

Kariel, H. and Kariel, P. "Socio-Cultural Impacts of Tourism: An Example from the Austrian Alps," Geografisker Annaler, Winter, 1982.

Mayor of Charleston's Tourism Management Committee. The Final Report of the Mayor of Charleston's Tourism Management Committee. The Center for Metropolitan Affairs and Public Policy, The College of Charleston, Charleston, S.C., 1982.

Noronha, R. Review of Sociological Literature on Tourism. New York: The World Bank, 1976.

Organization for Economic Co-Cooperation and Development (OECD), The Impact of Tourism on the Environment, Paris: OECD, 1980.

Plog, S. "Why Destination Areas Rise and Fall in Popularity," Cornell H.R.A. Quarterly, February, 1974.
Reime, M. and Hawkins, C. "Tourism Development: A Model for Growth," Cornell H.R.A. Quarterly, May 1979.

Richter, L. "The Political Uses of Tourism: A Phillipine Case Study," Journal of Developing Areas, January, 1980.

Rogers, E. Diffusion of Innovations. New York: The Free Press, 1962.

Smith, V. Hosts and Guests. Philadelphia: University of Pennsylvania Press, 1977

Stansfield, C. "Atlantic City and the Resort Cycle," Annals of Tourism Research, Vol. 5, 1978.

Stough, R., Feldman, M., Bosnic, B., Ashmore. J., and Noftzinger, N., Tourism Profile Study: Profile and Impact of the Charleston Metropolitan Area Tourism Industry 1982-1983. Charleston, South Carolina: Tourism Profile Study Committee (Charleston County Park, Recreation and Tourist Commission; Charleston Trident Chamber of Commerce; and, The City of Charleston, South Carolina), 1984.

Tantillo, R. "Casino Gambling and Urban Redevelopment," Paper presented at a conference at Stockton State College, Pamona, New Jersey, entitled "Atlantic City Tourism and Social Change," May 3, 1982. 